\title{
Experimental Performance of Turbine Reaction Flow Type Straight with Blade Ratio Variation
}

\author{
Priyo Heru Adiwibowo, A Grummy Wailanduw
}

\begin{abstract}
One of the forms of energy that can be harnessed is the energy potential of water, and use the turbine vortex is very useful to maximize the potential. The purpose of this study is to determine the power and efficiency resulting from the broad optimum of the turbine blade reaction flow vortex type of the blade cross-section is straight. This research uses experimental methods, namely by making the turbine vortex type blade section straight that has an area with blade ratio (BR) 0.90, 0.95 and 1. Load variation that is used the increase of 5000 grams to a round shaft on the turbine stops. Testing will be done to get the power and efficiency of the vortex flow. The highest power generated by the turbine with blade ratio 0.90 , which occurs on the capacity of $12,341 \mathrm{~L} / \mathrm{s}$ with a loading 40000 grams, has a power of 44,44 watts. The highest efficiency is produced by the turbine with a blade ratio 0.90 which occurs on the capacity of the $10,803 \mathrm{~L} / \mathrm{s}$ with a loading 45000 grams, has an efficiency of 53,82\%.
\end{abstract}

Keywords : blade ratio, vortex turbine, straight-Sided Blades

\section{INTRODUCTION}

At present, electrical energy is one of the most needed sources of energy for human life, both in the household, public and industrial sectors. At this time the energy that is still used in Indonesia still comes from fossil energy, namely oil and gas. Provision of electricity is already one of the obligations that must be met in each region for the economy to run. Based on data from the Director General of Renewable Energy and Energy Conservation of Energy and Mineral Resources, in 2011 Indonesia had the potential of Renewable Energy (EBT) of more than 158.288 MW. Hydropower is a type of renewable energy that has the greatest potential compared to other renewable energy sources. The potential of hydropower in Indonesia reaches 75.861 MW including the potential of mini / micro hydro resources. The total potential of New Renewable Energy is not entirely used as electricity generation, only about $6.8 \%$ of the total energy used by Indonesia.

The type of turbine used in PLTMH has many types classified based on the height of water falling into the turbine (head), one of which is the vortex turbine. Researcher from Germany Viktor Schauberger (1936) researched on a whirlpool-based water turbine (vortex). This type of turbine utilizes a whirlpool obtained from the spiral basin form of the turbine and then exits to an outlet located just below the

Revised Manuscript Received on January 10, 2020.

* Correspondence Author

Priyo Heru Adiwibowo, ${ }^{1}$ Department of Mechanical Engineering, Faculty of Enginering, Universitas Negeri Surabaya, Surabaya, Indonesia. Email: E-mail: priyoheruadiwibowo@unesa.ac.id

A Grummy Wailanduw, ${ }^{2}$ Department of Mechanical Engineering, Faculty of Enginering, Universitas Negeri Surabaya. Email: grummywailanduw@unesa.ac.id basin. This vortex turbine attracts the attention of an Austrian researcher, Franz Zotlöterer (2007), in his patent he stated that a vortex turbine can be used with the lowest water fall height of $0.7 \mathrm{~m}$. In his research the theoretical energy that can be converted has an efficiency of $80 \%$ and in an actual state an efficiency of $73 \%$ is obtained. At present, electrical energy is one of the most needed sources of energy for human life, both in the household, public and industrial sectors.

Research has also been carried out by Widiyatmoko (2012) entitled "Effect of Variations in the Number of Blades Against Electric Output on Vortex Turbines", research was conducted to determine the effect of the number of vortex turbine blades on total efficiency. The results obtained the highest efficiency of $6.02 \%$ in the number of blades 8 and 1.85 watts of power with a mechanical power verification of 3.44 watts. To increase the efficiency of the water turbine, a guide vane must be installed. This steering blade serves to direct the flow of water toward the turbine, so that the flow of water that hits the turbine can increase the turbine rotation and can increase turbine efficiency. In the application of the Francis turbine and Banki turbines the driver blade has been installed, but in the vortex turbine the driver blade has not been installed. Research conducted by Andrian Maidangkay (2014) entitled "Effect of Flow Direction Angle and Number of Single Wheel Hinged Radius Blades on Kinetic Turbine Performance" showed the results with $35^{\circ}$ directional blade angle is the most optimal angle with the highest efficiency at the number of 12 blades ie $33.241 \%$. The power and torque produced are 21.365 Watt and 3.864 Nm.

Research on guide vane has also been carried out by Moch. Asief Rosyidin, from this study it was found that the change in guide vane at different heads affected the performance of the cross flow air turbine. The largest WHP of $25.0957 \mathrm{kWatt}$ and the highest BHP of 7,7679 kWatt were obtained at $80 \%$ guide vane opening, head height of $13.75 \mathrm{~m}$ with a discharge of $0.2880 \mathrm{~m} 3 / \mathrm{s}$. The greatest efficiency is found in the opening of the $80 \%$ guide vane, head height of $13.55 \mathrm{~m}$ with a discharge of $0.2759 \mathrm{~m} 3 / \mathrm{s}$, which is $31.42 \%$. In this study shows that each opening angle of the directional blade has certain characteristics

With this research, it is expected that the most optimal inlet notch angle in a vortex turbine can be used as a reference in future studies.

\section{MATERIALS AND METHODS}

All materials and methods that have been used in the work must be stated clearly and subtitles should be used when necessary.

\section{A. Research variable}

The independent variable is the variable that influences or

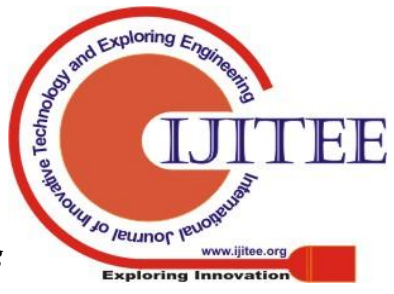




\section{Experimental Performance of Turbine Reaction Flow Type Straight with Blade Ratio Variation}

is the cause of the change or the appearance of the dependent variable. In this study, the independent variable is blade ratio using $0.90,0.95$ and 1 .

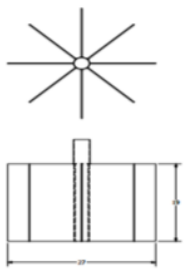

BR 0.90
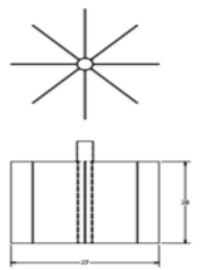

BR 0.95
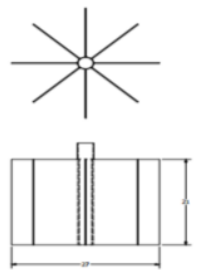

BR 1
Figure 1. Variation of blade ratio

The dependent variable is the variable that is affected or which is due, because of the independent variables. In this study the dependent variable is the power and efficiency produced in each variation of the steering blade.

Control variable is a control variable that is a variable that is controlled or made constant so that the influence of the independent variable on the dependent is not influenced by external factors not examined. In this study has several control variables, namely:

Basin height used is $70 \mathrm{~cm}$.

Steering blade material is made of iron plate $(2 \mathrm{~mm})$.

The turbine used is a vortex turbine with a number of 8 blades and a diameter of $21 \mathrm{~cm}$.

The turbine used uses type straight turbine.The diameter of the outlet basin is $9 \mathrm{~cm}$. The load variations used are $5000 \mathrm{~g}, 10000 \mathrm{~g}, 15000 \mathrm{~g}, 20000 \mathrm{~g}$, until stop.

The capacity used is $9.414 \mathrm{l} / \mathrm{s}, 10.803 \mathrm{l} / \mathrm{s}$ and 12,341 1/s.

\section{RESULTS AND DISCUSSION}

\section{A. Result}

Data retrieval is carried out three times, which is then taken the average value of the three data. The variation of blade ratio using $0.90,0.95$ and 1 .with loading of $5000 \mathrm{~g}$, $10000 \mathrm{~g}, 15000 \mathrm{~g}, 20000 \mathrm{~g}, 25000 \mathrm{~g}, 30000 \mathrm{~g}, 35000 \mathrm{~g}, 40000 \mathrm{~g}$ and the addition is made $1000 \mathrm{~g}$ before the turbine stops. This is done so that the data obtained is really valid. The values obtained from the test are shaft rotation, balance sheet value, and vortex height which are then processed to get the flowing water power, torque, turbine power, and efficiency. To obtain the above data, several calculations are needed, namely,

\section{- Calculation of Water Capacity}

Measurement of water capacity using the following equation:

$$
Q=C d \cdot \frac{8}{15} \cdot \sqrt{2 g} \cdot \operatorname{tg} \frac{\theta}{2} \cdot H^{\frac{5}{2}}
$$

- Flowing Water $(\mathrm{Pa})$

Theoretical water power can be calculated using the following equation:

- Torque (T)

Torque can be calculated using equations
Basin diameter used $56 \mathrm{~cm}$.

$$
T=F \cdot r
$$

- Angular Speed $(\omega)$

Turbine rotation speed is calculated using the equation:

$$
\omega=\frac{2 \pi n}{60}
$$

- Turbine Power (Pt)

Turbine power is calculated by the following equation:

$$
P t=T . \omega
$$

- Turbine Efficiency ( $\eta \mathrm{t})$

Efficiency can be calculated by the following equation:

$$
\eta=\frac{P t}{P a} x 100 \%
$$

Author (s) can send paper in the given email address of the journal. There are two email address. It is compulsory to send paper in both email address.

\section{B. Discussion}

a. The Effect of Blade ratio Variations on Power in Each Capacity

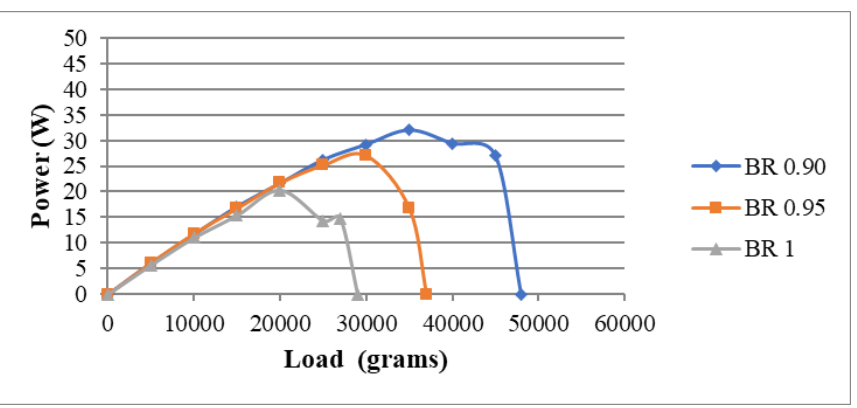

Figure 2. Effect of Blade ratio Variations on the Capacity 9.414 L/s on the Power Generated

Based on Figure 2 with the addition of the capacity of the surface area of the blade that is hit by the water becomes more so it is very influential on the resistance to the loading and the value of the power generated. From the graphic results obtained by a turbine with blade ratio of 0.90 to get the results of power continues to increase until the loading of 35000 grams by getting power results of 31,968 watts and decreased in power value until the turbine stops at 48000 grams of loading. At a blade ratio of 0.95 the value of the power generated continues to increase until the loading of 30000 grams to get the power output of 27.049 watts and experience a decrease in power until the turbine stops at 37.000 grams loading. At blade ratio of 1 the value of the power generated continues to increase until the loading of 20000 grams by getting the power output of 20.331 watts and has decreased power until the turbine stops at 29,000 grams of loading. From the results of these graphs and tables it can be concluded that the turbine at blade ratio of 0.95 with a capacity of $9.413 \mathrm{~L} / \mathrm{s}$ at a loading of 35000 grams has

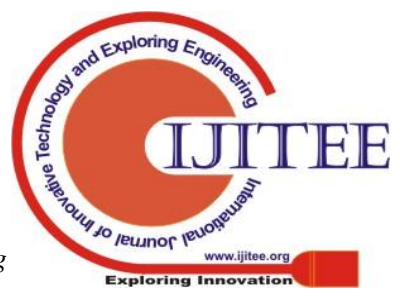


the highest power value of 31,968 watts. This happens because with increasing capacity, the surface area of the blade that is hit by the water becomes more, therefore the turbine is more resistant to high loading so that the power generated is greater.

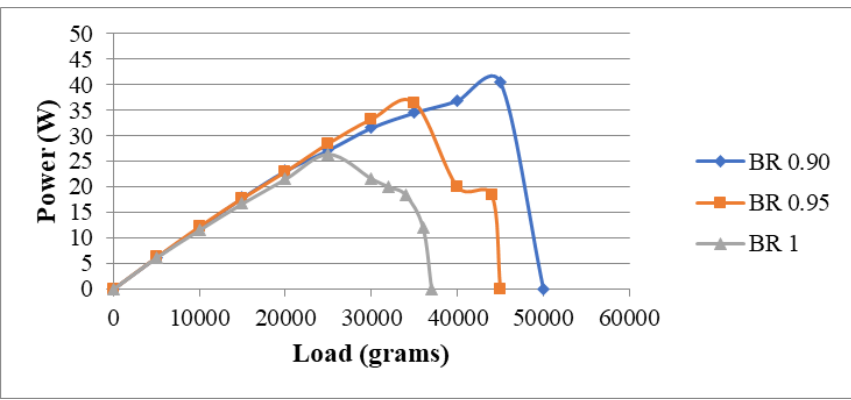

Figure 3. Effect of Blade ratio Variations on the Capacity 10.803 L/s on the Power Generated

Based on Figure 3, capacity addition is very influential on the resistance to the loading and the value of the power generated. At this capacity, the variation made on the turbine blade height tends to increase in the value of the power even though the condition is given a few moments when the load is not completely submerged. From the graphic results obtained by a turbine with blade ratio of 0.95 , the power results continue to increase until the loading of 45000 grams by getting a power output of 40.50 watts and a decrease in power value until the turbine stops at 50000 grams loading. At a blade ratio of 0.95 the value of the power generated continues to increase until the loading of 35,000 grams by getting the power output of 36,431 watts and experiencing a decrease in power until the turbine stops at 45,000 grams of loading. At a turbine blade height of $21 \mathrm{~cm}$, the value of the power generated continues to increase until the loading of 25000 grams by getting a power yield of 26,363 watts and has decreased power until the turbine stops at 37,000 grams loading. From the results of these graphs and tables it can be concluded that the turbine at blade ratio of 0.95 with a capacity of $10.803 \mathrm{~L} / \mathrm{s}$ at a loading of 45000 grams has the highest power value of 40.50 watts. This happens because increasing the capacity makes the turbine more resistant to high loading, so the power generated is greater.

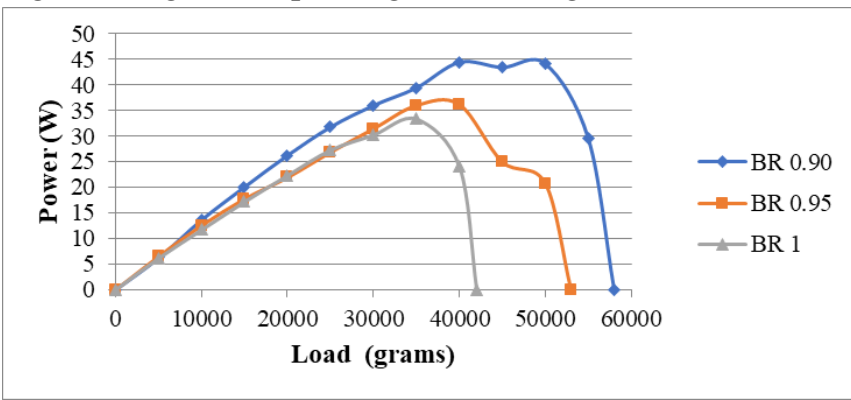

Figure 4. Effect of Blade ratio Variations on the Capacity 12.341 L/s on the Power Generated
Based on Figure 4 the addition of capacity is very influential on the resistance to the load and the value of the power generated. At this capacity, the variation made on the turbine blade height tends to increase in the value of the power even though the condition is given a few moments when the load is not completely submerged. From the graphic results obtained by a turbine with blade ratio of 0.90 , the power results continue to increase until the loading of 40000 grams by getting a power output of 44.444 watts and a decrease in the value of power until the turbine stops at 58,000 grams. In blade ratio of 0.95 , the value of the power generated continues to increase until the loading of 40000 grams by getting the power output of 36.203 watts and experiencing a decrease in power until the turbine stops at 53000 grams loading. At a turbine blade height of $21 \mathrm{~cm}$, the value of the power generated continues to increase until the loading of 35,000 grams by getting the power output of 33.421 watts and decreases in power until the turbine stops at 42,000 grams of load. From the results of these graphs and tables it can be concluded that the turbine at blade ratio of 0.90 with a capacity of $12,341 \mathrm{~L} / \mathrm{s}$ at 40000 grams loading has the highest power value of 44,441 watts. This happens because increasing the capacity makes the turbine more resistant to high loading, so the power generated is greater.

\section{b. The Effect of Blade ratio Variations on Efficiency in Each} Capacity

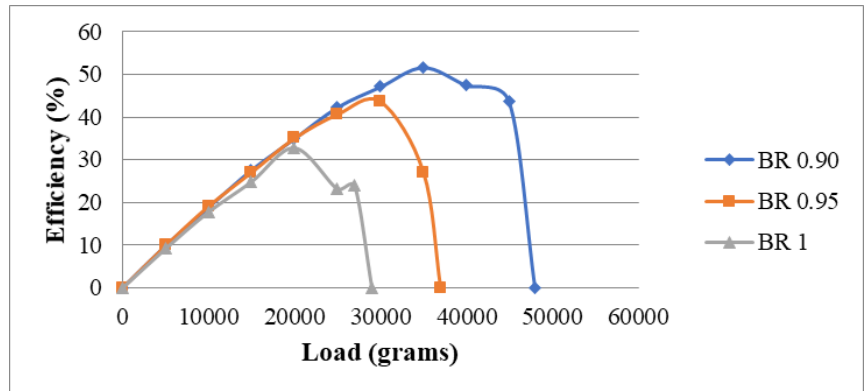

Figure 5. Effect of Blade ratio Variations on the Capacity 9.309 $\mathrm{L} / \mathrm{s}$ on the Generated Efficiency

Based on Figure 5 capacity addition is very influential on the load resistance and the resulting efficiency value. At a capacity of $9.414 \mathrm{~L} / \mathrm{s}$, variations in the turbine blade height tend to increase in efficiency even though the condition of some turbines when given loading is not completely submerged. From the graph the turbine with blade ratio of 0.90 , the resulting efficiency value continues to increase until the loading of 35000 grams with the resulting efficiency of $51.665 \%$ and decreases the efficiency value until the turbine stops at 48000 grams loading. In blade ratio of 0.95 , the resulting efficiency value continues to increase until the loading of 30000 grams with the resulting efficiency of $43.715 \%$ and decreases the value of efficiency until the turbine stops at 37000 grams loading. In turbines with blade ratio of 1 , the resulting

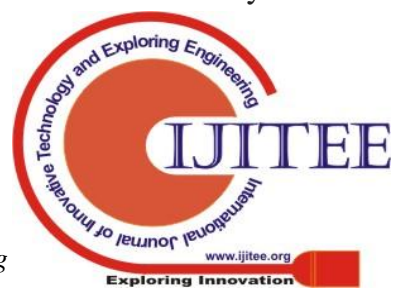




\section{Experimental Performance of Turbine Reaction Flow Type Straight with Blade Ratio Variation}

efficiency value continues to increase until the loading of 20000 grams with the resulting efficiency of $32.859 \%$ and decreases in efficiency until the turbine stops at 29,000 grams. From the results of these graphs and tables it can be concluded that the turbine with blade ratio of 0.90 with a capacity of $9.413 \mathrm{~L} / \mathrm{s}$ at the loading of 35000 grams has the highest efficiency value of $51.665 \%$. This happens because with increasing capacity, the surface area of the blade that is hit by the water becomes more.

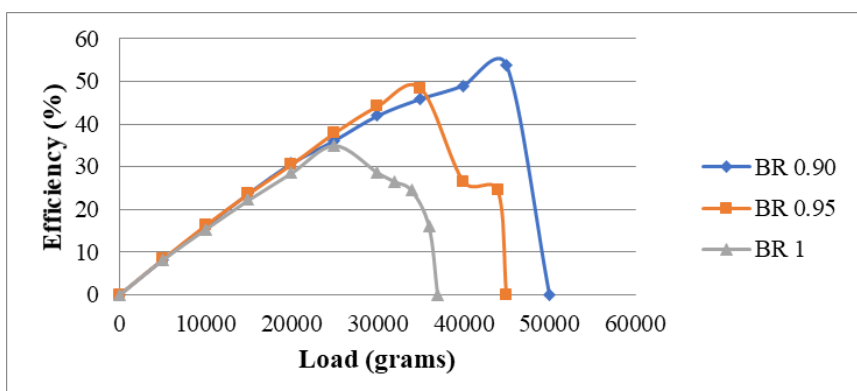

Figure 6. Effect of Blade ratio Variations on the Capacity 11.042 L/s on the Generated Efficiency

Based on Figure 6, the additional capacity is very influential on the load resistance and the resulting efficiency value. At a capacity of $10,803 \mathrm{~L} / \mathrm{s}$, variations in the turbine blade height tend to increase in efficiency. With increasing capacity, the surface area of the blade that is hit by the water becomes more so that the turbine is more resistant to high loading and the resulting greater efficiency value. From the graph the turbine with blade ratio of 0.90 , the resulting efficiency value continues to increase until the loading of 45000 grams with the resulting efficiency of $53.823 \%$ and decreases in the value of efficiency until the turbine stops at the loading of 50000 grams. In blade ratio of 0.95 , the resulting efficiency value continues to increase until the loading of 35000 grams with the resulting efficiency of $48.416 \%$ and decreases in the value of efficiency until the turbine stops at 45,000 grams loading. In turbines with blade ratio of 1 , the resulting efficiency value continues to increase until the loading of 25000 grams with the resulting efficiency of $35.035 \%$ and decreases in the value of efficiency until the turbine stops at 37000 grams loading. From the results of these graphs and tables it can be concluded that the turbine with blade ratio of 0.90 with a capacity of $10.803 \mathrm{~L} / \mathrm{s}$ at a loading of 45000 grams has the highest efficiency value of $53.823 \%$

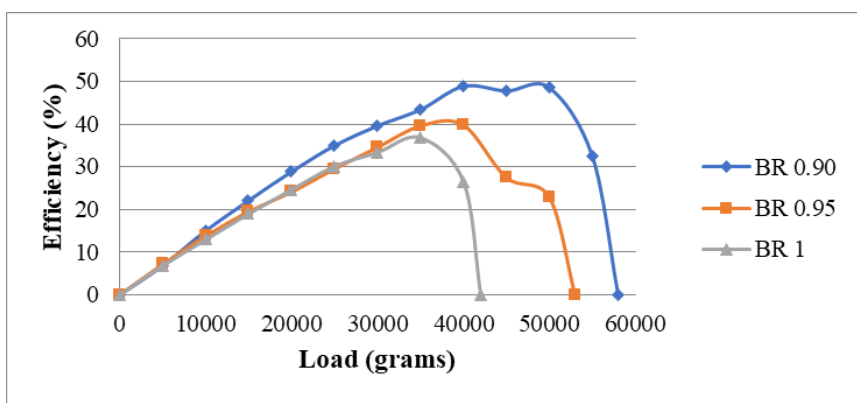

Figure 7. Effect of Blade ratio Variations on the Capacity $13.443 \mathrm{~L} / \mathrm{s}$ on the Generated Efficiency
Based on Figure 7, capacity addition is very influential on the load resistance and the resulting efficiency value. At a capacity of $12,341 \mathrm{~L} / \mathrm{s}$ the variation made to the height of the turbine blade tends to decrease in the value of efficiency, although with increasing capacity the surface area of the blade affected by the water hit will be more but not all the additional capacity and loading get a higher value of the resulting efficiency. From the graph the turbine with blade ratio of 0.90 , the resulting efficiency value continues to increase until the loading of 40000 grams with the resulting efficiency of $48.944 \%$ and decreases the efficiency value until the turbine stops at 58000 grams loading. In blade ratio of 0.95 , the resulting efficiency value continues to increase until the loading of 40000 grams with the resulting efficiency of $39.872 \%$ and decreases in the value of efficiency until the turbine stops at 53000 grams loading. In turbines with blade ratio of 1 , the resulting efficiency value continues to increase until the loading of 35000 grams with the resulting efficiency of $36.808 \%$ and decreases in the value of efficiency until the turbine stops at 42000 grams loading. From the results of these graphs and tables it can be concluded that the turbine with blade ratio of 0.90 with a capacity of $12,341 \mathrm{~L} / \mathrm{s}$ at 40000 grams loading has the highest efficiency value of $48,944 \%$. The more surface area of submerged turbine blade has more influence on the value of efficiency resulting from turbine conditions that are resistant to loading, even though the turbine is completely submerged.

\section{CONCLUSION}

- A conclusion section is not required. Although a conclusion may review the main points of the paper, do not replicate the abstract as the conclusion. A conclusion might elaborate on the importance of the work or suggest applications and extensions. The highest power is in the turbine with blade ratio of 0.90 with a capacity of 12,341 L / s with a power rating of 44,441 watts at 40000 gram loading, followed by a turbine with blade ratio of 0.95 with a capacity of $12,341 \mathrm{~L} / \mathrm{s}$ with a value of 36,203 watts at 40000 grams, and the lowest is found in turbines with blade ratio of 1 with a capacity of $12,341 \mathrm{~L} / \mathrm{s}$ with a power value of 33.421 watts at a loading of 35000 grams.

- The highest efficiency was found in turbines with blade ratio of 0.90 with a capacity of $10.803 \mathrm{~L} / \mathrm{s}$ with an efficiency value of $53.823 \%$ at a loading of 45000 grams, followed by turbines with blade ratio of 0.95 with a capacity of $10.803 \mathrm{~L} \mathrm{/} \mathrm{s} \mathrm{with} \mathrm{an} \mathrm{efficiency} \mathrm{value} \mathrm{of}$ $48.416 \%$ at a loading of 35000 grams, and the lowest is found in turbines with blade ratio of 1 with a capacity of $10.803 \mathrm{~L} / \mathrm{s}$ with an efficiency value of $35.035 \%$ at a loading of 25000 grams. 


\section{REFERENCES}

1. Khurmi, R.S., (1987). A Textbook of Hydraulics, Fluid Mechanics and Hydraulics Machines., S. Chand Ltd.

2. Maidangkay, Adrian, Rudy Soenoko, Slamet Wahyudi., (2014). Effect of Flow Direct Angle and Number of Single Spindle Radius Spoon Radius on Kinetic Turbine Performance, Department of Mechanical Engineering, Faculty of Engineering, Universitas Brawijaya Malang.

3. Mulligan, S., and P. Hull., (2010). Design And Optimisation Of Water Vortex Hydropower Plant.

4. Munson, Bruce, R., Young, Donald, F., Okiishi, Theodore, H., (2006) .Fundamentals Of Fluid Mechanics Fifth Edition. ,Jhon Wiley \& Sons Inc.

5. Rosyidin, Moch. Asief, Djoko Sutikno, Sugiarto., (2013). Effect of Flow Direction Angle and Number of Single Wheel Hinged Radius Blades on Kinetic Turbine Performance, Department of Mechanical Engineering, Faculty of Engineering, Universitas Brawijaya Malang.

6. Widiyatmoko., (2012). Effect of Variations in Number of Blades on Electric Power Output in Vortex Turbines, Magister FT System Engineering Yogyakarta.

7. Zotloterer, Franz., (2007). Zotloterer Gravitational Vortex Plant.

\section{AUTHORS PROFILE}

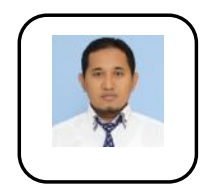

Priyo Heru Adiwibowo, is a Lecture of engineering at the State University of Surabaya-Indonesia. He was head of the study program S1 of Mechanical Engineering Department, Faculty of Engineering State University of Surabaya -Indonesia (2016-2022). He got S2 from Institute of Technology Sepuluh Nopember. junior editor of Otopro Journal, Machine Engineering Department, Faculty of Engineering State University of Surabaya, an Assessor for Vocational Senior High School in East Java Province, Indonesia.

Published research entitled Force coefficient characteristics on a four circular cylinders in an in-line square configuration near a plane wall at "small gap", AIP Conference Proceedings 2187, 020025 (2019), https://doi.org/ 10.1063 / 1.5138280, https://doi.org/10.1063/1.5046585, Numerical simulation of flow across a four-cylinder circular arrangement at a ratio L / D $=3.0$ near the wall, Journal of Machines, ITB, Vol. 25, No. 1, (2016), 29-40

He membership BKSTM and he also participated in Bridging in Universitas NTUST Taipe, Taiwan, (February 2013 - March 2013).

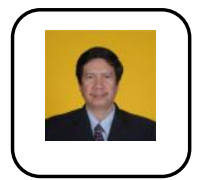

A Grummy Wailanduw, is a Doctor of engineering at the State University of Surabaya-Indonesia. He got PhD from Institute of Technology Sepuluh Nopember. For the time being, he serves as Chief Editor of the journal of Otopro Journal, Mechanical Engineering Department, Faculty of Engineering State University of Surabaya, an Assessor for Vocational Senior High School in East Java Province, Indonesia. Published research entitled Force coefficient characteristics on a four circular cylinders in an in-line square configuration near a plane wall at "small gap", AIP Conference Proceedings 2187, 020025 (2019), https://doi.org/ 10.1063 / 1.5138280, Numerical simulation of cross-flow around four circular cylinders in an in-line square configuration with the critical spacing ratio "L / D" near a plane wall, AIP Conference Proceedings 1984, 020001 (2018); https://doi.org/10.1063/1.5046585, Numerical simulation of cross-flow around four circular cylinders in line square configuration near a plane wall at supercritical Reynolds number AIP Conference Proceedings 1983, 020024 (2018); https://doi.org/10.1063/1.5046220, Numerical simulation of flow across a four-cylinder circular arrangement at a ratio L / D $=3.0$ near the wall, Journal of Machines, ITB, Vol. 25, No. 1, (2016), 29-40, Numerical simulation of cross-flow around four circular cylinders in-line square configuration near a plane wall, ARPN Journal of Engineering and Applied Sciences, Vol.11, No.2, January 2016, Flow around two side-by-side circular cylinders with intermediate spaced near a plane wall, Journal of Advances and Applications in Fluid Mechanics, Vol. 18, No.2, October 2015 